\title{
PORQUE O TERMO OPERANTE NÃO É SINÔNIMO DE COMPORTAMENTO: COMENTÁRIOS
}

\section{WHY OPERANT IS NOT SYNONYMOUS OF BEHAVIOR: COMMENTS}

\author{
JOÃO CLAUDIO TODOROV
}

UNIVERSIDADE DE BRASÍLIA, BRASIL

E

\section{MARCELO BORGES HENRIQUES}

\author{
UNIVERSIDADE DE BRASíLIA E UNIVERSIDADE FEDERAL DE GOIÁs, BRASIL
}

\begin{abstract}
RESUMO
Em 2012, Todorov argumentou que a definição de comportamento como interação organismo-ambiente não só não representa o objeto de estudos da Análise do Comportamento como também é incompatível com o seu uso corrente. Apesar de o artigo não oferecer uma definição de comportamento, ele inspirou este volume especial da Revista Brasileira de Análise do Comportamento em que diferentes autores discutem a definição. O presente artigo oferece uma visão crítica e comenta os artigos que examinaram o termo. Perante a revisão, foi possível observar que em dois artigos o termo é definido por meio do conceito de operante. Um terceiro artigo apresenta comportamento, de forma mais ampla, com uma definição próxima à noção de contingência, enquanto que o último artigo analisado sugere um check list para se localizar comportamento como uma ocorrência. Qual das visões será mais ou menos aceita dependerá das práticas verbais dos analistas do comportamento no ambiente cultural selecionador. Seja como for, procuramos esclarecer os equívocos na utilização de comportamento com os sentidos propostos.
\end{abstract}

Palavras-chave: operante, contingência, comportamento.

\begin{abstract}
In 2012, Todorov argued that the definition of behavior as the interaction between organism-environment is incompatible with its current use in behavior analysis. Although the article did not provide a definition of behavior, it inspired this special issue of the Revista Brasileira de Análise do Comportamento / Brazilian Journal of Behavior Analysis in which different authors discuss the definition. In this article, we examine such articles and offer insights on the definitions proposed by the authors. We noted that in two of them the term was defined by the concept of the operant. A third article defines the term more broadly, with a conception close to the definition of contingency, whereas the last one suggests a checklist to track behavior as an instance. Which view is more or less accepted will depend on the verbal practices of behavior analysts in face of the selecting cultural environment. At any rate, we tried to clarify misconceptions about the uses proposed by authors.
\end{abstract}

Keywords: operant, contingencies, behavior.

João Claudio Todorov, Departamento de Ciências do Comportamento, Universidade de Brasília; Marcelo Borges Henriques, Departamento de Ciências do Comportamento, Universidade de Brasília e Departamento de Psicologia, Universidade Federal de Goiás. J. C. Todorov é Bolsista de Produtividade Científica 1D do CNPq. Partes deste trabalho foram publicadas no blog jctodorov.blogspot.com.br. E-mail: todorov@unb.br 
É salutar a iniciativa da Revista Brasileira de Análise do Comportamento (REBAC) em promover o debate sobre o termo comportamento. A revista apresenta cinco artigos escritos por diferentes autores que abordam o termo de diferentes pontos de vista. Aparentemente pacífico, o termo é controverso e posta problemas ainda não resolvidos sobre seu uso. Esta revisão crítica comenta e discute especificamente quatro artigos que examinaram o termo comportamento e defende a tese de que a literatura, de maneira geral, define comportamento por meio do operante.

\section{CENÁRIO DO PRINCIPAL OBJETO DE CONTEMPLAÇÃO}

$\mathrm{O}$ artigo que inspirou este número especial, "Sobre uma Definição de Comportamento" (Todorov, 2012), é muito claro: não oferece uma definição. O artigo de Todorov (2012) argumenta que a definição em voga no Brasil é incompatível com o uso do termo na Análise do Comportamento. Todorov destaca que o termo é definido como interação organismo-ambiente, mas seu uso não é feito com esse sentido. Há algumas décadas, o termo passou a ser sinônimo daquilo que o organismo faz. Sem sombra de dúvida, o comportamento propositivo (operante) ocupa as principais páginas dos periódicos de Análise do Comportamento. Contudo, o termo operante foi introduzido para lidar com a simples observação de que haveria uma outra relação condicional além da contingência respondente responsável por aquilo que o organismo faz (Catania, 1973), e não para substituir o uso do termo comportamento.

\section{UM BREVE RELATO DOS PRINCIPAIS PONTOS DOS ARTIGOS}

Embora o contexto para este número especial da REBAC tenha sido o artigo supracitado, os autores convidados parecem estar respondendo a um chamado para definir comportamento. Enquanto alguns artigos citam o trabalho apenas passageiramente, há um artigo que sequer cita a obra. Objetivando dar uma definição, cada um dos trabalhos aborda o assunto à sua maneira.

Carrara e Zilio (2013) no artigo intitulado "O Comportamento Diante do Paradigma Behaviorista Radical" apresentam uma espécie de taxonomia dos usos (e desusos) do termo comportamento dentro e fora do âmbito da Análise do Comportamento. O leitor é conduzido pela análise de termos auxiliares, aquilo que os autores denominam de condicionantes lógicos para a definição de comportamento. Apesar de os autores declararem não ter pretensões de definir o termo "esperamos, entrementes, que apesar de não ser aqui oferecida uma definição pretensamente 'definitiva' de comportamento, estejam bastante claras para o leitor nossas reflexões e sugestões de encaminhamento" (p. 17) - eles não só conduzem o leitor a uma conclusão, mas acabam por destacar uma preferência; comportamento como funcionamento do organismo que faz intercâmbio com o ambiente, "(commerce) no sentido de que é afetada por consequências do ambiente externo da mesma forma em que o operante o faz, aspecto que é o interesse prioritário deste ensaio" (p. 15). "Não há como falar do comportamento em si, mas somente nas suas relações com o ambiente" (p. 14).

O primeiro termo auxiliar apresentado por Carrara e Zilio (2013) é "relação". O conceito de relação, para os autores, deriva-se de seu uso na lógica matemática. $\mathrm{Na}$ teoria dos conjuntos, uma relação é um nexo de dependência e pode significar covariação, algo próximo ao conceito de contingência; variação concomitante. Carrara e Zilio assumem que há uma lógica relacional entre comportamento, condições antecedentes e consequentes, uma vez que o termo relação é amplamente utilizado por analistas do comportamento. Outro termo auxiliar analisado é "evento". Segundo os autores, é outro termo largamente utilizado na área, por vezes confundido com o estado de "coisas". Esclarecem que o termo denota "ocorrências", ou seja, um acontecimento com dimensões temporais bem definidas (i.e., apesar de dinâmico e processual, eles ocupam tempo), mas, em contrapartida, dimensões espaciais relativamente indefinidas (i.e., o resultado ou acontecimento possui diferentes estágios). Objetos podem ser deslocados ou retidos, mas ocorrências somente podem ser registradas. Como o termo evento é utilizado para designar os componentes de uma relação condicional, os autores se perguntam se "seria viável designar o comportamento como um evento que intermedia as relações entre organismo e ambiente, tal como 'resposta' no paradigma da tríplice relação de contingências?" (Carrara \& Zilio, 2013, p. 4).

Os autores afirmam ser a Análise do Comportamento "usualmente descrita como ciência das interações organismo-ambiente" (Carrara \& Zilio, 2013, p. 6) e se perguntam "o que caracteriza a interação estudada na Análise do Comportamento? A resposta a essa questão talvez esteja ligada à própria definição de comportamento" (p. 6). A resposta dos autores se ligará à proposta Skinneriana de comportamento, com destaque para a participação do termo organismo na definição. $\mathrm{O}$ destaque serve para fortalecer a argumentação de que o organismo interage no ambiente e que a interação se dá pelo comportamento.

\begin{abstract}
"Skinner sinaliza que o local de sua ocorrência é o próprio organismo, mas também esclarece que, nessa ocasião, o organismo está interagindo com o ambiente, sobre o qual age ou com qual, de alguma maneira, interage" (Carrara \& Zilio, 2013, p. 12).
\end{abstract}

Comportamento é aquilo que o organismo faz; é parte do seu funcionamento global. Neste sentido, os eventos ambientais devem incidir nos órgãos sensoriais de organismos, uma vez que comportamento não possui tais órgãos. "Note-se, portanto, que quem é sensível às mudanças ambientais é o organismo individual" (Carrara \& Zilio, 2013, p. 15), "quem contata o ambiente é o organismo e o que muda é o corpo, 'reconfigurado' "(Carrara \& Zilio, 2013, p. 13-14). “A mudança na 'configuração' comportamental tem natureza histórica, no sentido de que decorre das interações organismoambiente; de modo correspondente, o corpo muda a cada 
interação" (Carrara \& Zilio, 2013, p. 14).

Para que haja comportamento, é preciso o corpo que se comporta. Mas um corpo não seria suficiente; é preciso que o corpo esteja em funcionamento. Para os autores, o funcionamento de interesse é aquele que mantém intercâmbio (i.e., é afetado por consequências). Se é o organismo quem interage, então não pode ser o comportamento quem interage, comportamento só pode ser interação (especificamente a operante). Como apontado anteriormente, Carrara e Zilio (2013) optam por ficar com a interpretação de comportamento como a interação organismo-ambiente, pois só assim acham justificativa para os termos "Análise do Comportamento" e "Analistas do Comportamento".

Nesse contexto, se uma definição relacional de comportamento fosse adotada, então faria sentido (semanticamente) nomear a área de "Análise do Comportamento" ao mesmo tempo em que a descrevemos como uma "ciência das interações entre organismo e ambiente" que se instrumentaliza pela identificação e descrição de relações funcionais. Porém, se a definição não relacional for a escolhida, então há certa imprecisão entre o nome da área e a descrição do seu objeto. Analistas do comportamento, nesse caso, analisam interações e estas não seriam equivalentes a comportamento, já que este seria apenas parte da relação. Assim, "Análise do Comportamento" seria um título incompleto, pois apresenta apenas parte do que é, de fato, analisado. Que caminho devemos trilhar em nossas incursões conceituais? (Carrara \& Zilio, 2013, p. 6-7)

"O Comportamento Diante do Paradigma Behaviorista Radical" nos oferece um panorama amplo das tentativas de definição de comportamento, com ênfase no trabalho de B. F. Skinner e ajuda na argumentação de Todorov (2012) sobre a incongruência da definição de comportamento como a interação organismo-ambiente. Note-se que Carrara e Zilio (2013) têm objetivo diferente de Todorov (2012). Os autores buscam na história uma definição de comportamento e concluem que a Análise do Comportamento usa o termo sem uma definição precisa, enquanto Todorov (2012) apenas argumenta que uma dada definição em voga é inconsistente, ilógica e confunde o leitor.

No artigo "O conceito de comportamento operante como problema”, de Sílvio Botomé (2013), são discutidos os principais termos conceituais da Análise do Comportamento, e a importância destes para se definir comportamento, considerando-o "o" objeto de estudo, posição muito próxima à de Carrara e Zilio (2013). Logo ao início do artigo, cita Russell para destacar como seus escritos influenciaram Skinner. Ao longo do texto, o autor afirma que "estudar apenas uma parte da interação da ação humana com o mundo" (Botomé, 2013, p. 20) mantém o "cenário inerte". Sem dúvidas ele está falando da contingência respondente, e essa crítica permite que o autor apresente sua posição em relação ao comportamento. Explicitamente Botomé (2013) assume que irá analisar o conceito de operante para abstrair o conceito de comportamento.
Botomé (2013) revisa definições de comportamento e vai além revisando conceitualmente usos de termos como contingência de reforço, reforço, entre outros, oferecendo novas definições:

O comportamento como um sistema de interações entre classes de aspectos de um ambiente, classes de atividades de um organismo e classes de aspectos de um ambiente subsequente às atividades desse organismo constitui o objeto de exame desse texto (p. 19).

"Reforçado" constituirá uma característica do conjunto de interações entre os três componentes, conforme as características dos eventos subsequentes à atividade de um organismo, e não da atividade do organismo a qual aumentou a probabilidade de ocorrência. A alteração na frequência de ocorrência das atividades de uma classe é uma evidência que indica que, provavelmente, há uma relação estabelecida entre três componentes com certo grau de força ou resistência (...) (p. 38).

Discorre sobre a contribuição da análise experimental do comportamento para compreensão da ação humana, "o comportamento (como categoria ampla de fenômeno) tem sido cada vez mais examinado em tipos, em extensão e em profundidade" (Botomé, 2013, p. 21). Para o autor, cada relação desvelada é a descoberta de um novo tipo de comportamento. Vale lembrar que análise experimental do comportamento estuda prioritariamente a relação operante, logo os tipos desvelados são operantes.

As transformações do conceito de comportamento, desde as contribuições no estudo do comportamento reflexo até as mais recentes descobertas e construções conceituais a respeito do comportamento operante são uma das, talvez, mais importantes elaborações quanto aquilo de que se ocupa a Psicologia (Botomé, 2013 p. 22-23).

É possível perceber que o autor utiliza reflexo e operante como adjetivos de comportamento, portanto os considera como formas de comportamento. Falar sobre uma evolução ou transformação do conceito de reflexo ao operante, nomeando ambos como comportamento, serve ao propósito lógico de argumentar que o termo comportamento significa interação. Afirma que...

"a partir de 1938, Skinner descobriu e construiu, para a Psicologia, o conceito de 'comportamento operante', enfatizando outra interação [itálicos inseridos] que não mais aquela que caracterizava o comportamento reflexo" (Botomé, 2013, p. 25).

Mesmo destacando que há diferentes tipos de interações, insiste:

O termo 'operante', mesmo quando não explicito, vai ser o 'tipo' de comportamento (não mais em um sentido genérico) a que vai ser feita referência no âmbito das contribuições e entendimento da Análise do Comportamento (Botomé, 2013, p. 23). 
O autor opta por se comprometer com o conceito de operante como definição de comportamento, pois, para ele, o comportamento propositivo, como categoria ampla de comportamentos, abarca os respondentes. Considera possível utilizar o conceito de operante como intercambiável com comportamento. $\mathrm{O}$ autor afirma que os "componentes da unidade denominada 'comportamento reflexo', seriam: classes de respostas e classes de estímulos" (Botomé, 2013, p. 25). Citando a si mesmo, assevera o conceito de comportamento como "interação entre características das respostas de uma classe, características de classes de aspectos do ambiente antecedente e características de classes de aspectos do ambiente subsequente ou decorrente dessas respostas" (Botomé, 1980, citado por Botomé, 2013, p. 23). Indubitavelmente uma definição de operante.

Gradativamente a definição de operante e de comportamento se aproximam da noção de contingência. Botomé (2013), por exemplo, prefere utilizar a expressão atividade a comportamento, provavelmente por considerar que comportamento seja uma relação específica entre os três elementos da tríplice contingência.

Conforme acontecerem os três tipos de eventos, principalmente o que for subsequente à atividade do organismo, eles constituirão um ou outro comportamento [itálico inserido] (...) a caracterização das relações entre atividade e eventos subsequentes, completou as relações entre os eventos antecedentes e a atividade do organismo e a alteração do ambiente após a atividade do organismo mostrou ter propriedades múltiplas que constroem ou delimitam as demais relações, tornando-as mais ou menos fortes (ou fortalecidas) (Botomé, 2013, p. 42).

Diferente de Carrara e Zilio (2013), Botomé (2013) considera que as consequências - ou os eventos subsequentes como prefere denominar - não modificam o organismo, mas as características de suas atividades, por consequência o comportamento. Apesar desta consideração, o termo comportamento é sempre vinculado à expressão organismo.

A insistência em revisar conceitualmente cada conceito que considera pertinente para a definição e a redundância na argumentação em torno dos conceitos de comportamento, operante e contingência, parece ser em resposta crítica ao artigo de Todorov (2012). Em alguns momentos, o autor transparece discordar do posicionamento de Todorov e, por isso, gasta tantas linhas com o detalhamento de termos utilizados no artigo líder.

O terceiro artigo a ser apresentado é intitulado "Um estudo sobre definições de comportamento". Lazzeri (2013) atende ao chamado para definir comportamento trabalhando com os instrumentos de quem acha que uma definição deve ter tais e quais características, enquanto Todorov (2012), com menos fôlego, apenas apontou restrições lógicas ao uso de uma definição em voga. Seu texto apresenta um método bem descrito e claramente apresentado. O objetivo de Lazzeri é abstrair o conceito de comportamento com base naquilo que já se sabe sobre o conceito no seu uso cotidiano. Com a finalidade de remover outras interpretações de comportamento que não a de comportamento propositivo, o autor elenca desideratos que considera serem básicos para seu propósito.

A introdução do artigo permite ao leitor acompanhar a análise com clareza. O leitor, desde o início, torna-se ciente de que o objetivo da análise não é desvelar a estrutura subjacente ao conceito, ou seja, a sua essência, mas de apresentar um uso que possa ser condizente com a Psicologia ou, de modo mais geral, com as ciências comportamentais. Lazzeri (2013) argumenta que há diferentes usos ordinários do termo comportamento, mas se compromete com a noção ordinária de "comportamento enquanto ocorrência de uma ação ou reação de um organismo" (p. 48). "Trata-se de algo emitido ou realizado por (tipicamente) um organismo, em um momento e um local específicos" (p. 48).

A acepção adotada por Lazzeri (2013) assemelhase aos elementos apresentados pelos outros autores, por exemplo, a necessidade de ser um resultado de um organismo. É excluído do seu uso o movimento de objetos inanimados ou o movimento incidental do organismo (seja por ele mesmo ou por força de objetos). Um elemento adicional aos dois primeiros autores é a possibilidade de inclusão de comportamentos envolvidos na contingência respondente. Ao esclarecer a possibilidade de comportamentos envolvidos em contingências respondentes, o autor preocupa-se em distinguir reações de coisas que acontecem por inteira força de objetos. A diferença residiria no fato de as reações deverem "sua existência, em parte, a interações passadas com o ambiente - podendo ser no âmbito filogenético ou no ontogenético" (Lazzeri, 2013, p. 49). Isso implica que para definir ou localizar um comportamento, deve-se atentar para o fato de esse comportamento ser ou não fruto de uma interação. Portanto, comportamentos...

são fenômenos que dependem não só de mudança ou movimento de um organismo, mas também a outras propriedades. Logo, mudança ou movimento de um organismo não constitui uma condição suficiente" (Lazzeri, 2013, p. 50).

Mas se comportamento for fruto de uma interação, quais são os elementos da interação. Essa acepção parece eliminar o comportamento como um evento da interação, para considerá-lo um produto da interação. Dizer que comportamento é um evento cuja "sobrevivência" depende de interações, é bem diferente de dizer que ele é interação.

Lazzeri (2013) também discute termos como resposta e classe de respostas. Sua opção é por delimitar comportamento como uma ocorrência em momento e local específico, aproximando-se, explicitamente, ao conceito de resposta. Mais à frente, o autor apresenta uma acepção de comportamento como classe. Para o autor, comportamento como ação ou reação implica referência implícita a uma classe, apesar de considerar ambas as acepções distintas e preferir lidar com ocorrências do que 
padrões. Acredita-se que, para todos os autores, comportamento seja um conceito diferente do de resposta, a despeito dos diferentes sentidos entre eles.

$\mathrm{O}$ autor utiliza o restante do artigo para especificar as qualidades que delimitam o uso do termo comportamento. $\mathrm{O}$ autor não se restringe à Análise do Comportamento e faz um levantamento de definições de comportamento na ciência em geral e na filosofia, e as aprecia. Chama a atenção para como as definições corrompem ou não seus desideratos. Para o autor, basta apresentar uma representação panorâmica do uso ordinário do conceito para evitar a confusão. Por tal motivo, não conclui seu artigo com uma definição. Sugere duas definições possíveis: "Comportamento é aquilo que um organismo faz que possui uma ou mais funções (que devem ser entendidas, resumidamente falando, em termos de histórias de seleção filogenética ou ontogenética) e cuja etiologia envolve parcialmente fatores do ambiente presente como estímulos sensoriais" (p. 63).

Comportamento é aquilo que um organismo faz cuja etiologia envolve (em parte) processos seletivos na filogênese ou na ontogênese do organismo e (em parte) fatores do ambiente presente atuando como estímulos sensoriais." (Lazzeri, 2013, p. 63).

É importante destacar que a interpretação oferecida por Lazzeri (2013) mantém certo nível de compromisso com a Análise do Comportamento. As duas definições propostas por Lazzeri estão próximas da noção de contingência. Quando inclui em sua definição aspectos etiológicos ou quando argumenta que o comportamento deve ter uma ou mais funções, está, deliberadamente, comprometido com o objeto de estudos da Análise do Comportamento.

Por último, Tonneau (2013) realiza uma análise mais simples e concisa do que os demais autores, também mais heurística. "Instead of saying what behavior is, I have listed four criteria that any episode must fulfill, minimally" (p. 72). Diferente dos autores anteriormente apresentados, deixa claro que as definições de comportamento, em particular a primeira definição feita por Skinner, não incluem todas as atividades, somente as propositivas. Sua revisão conceitual busca na pele do organismo os limites geográficos da definição de comportamento e, em alguma medida, se emparelha com a proposta de Todorov (2012).

A simplicidade advém da iniciativa de fazer uma revisão conceitual da definição de comportamento proposta por Skinner em The Behavior of Organisms (1938). A iniciativa é edificante uma vez que trabalha com uma das primeiras tentativas de se definir comportamento na Análise do Comportamento. Como é a partir desse ponto que analistas do comportamento começam o seu empreendimento científico e suas digressões teóricas, então nada mais conveniente do que revisar a definição inicial. O que é interessante é que Tonneau (2013) vai considerar que não há uma, mas várias definições de comportamento na referida obra Skinner.
Para Tonneau (2013), o elemento central da definição de Skinner é a sentença em que ele afirma ser comportamento "that part of the functioning of an organism which is engaged in acting upon or having commerce with the outside world" (Skinner, 1938, p. 6, citado por Tonneau, 2013, p. 67). O trecho é importante, pois enraíza todas as outras sentenças de Skinner sobre o termo, por exemplo, a necessidade de ser observável. O autor esclarece que um evento "does not qualify as behavioral because it is observable or easily observable (...) behavior is easily observable because it is behavioral" (Tonneau, 2013, p. 68). O que é interessante de notar é que o autor faz questão de destacar que a ocorrência de comportamentos pode ser percebida pelos órgãos sensoriais, mas que não é isso que define comportamento. Semelhante à proposta de Todorov (2012), e Todorov e Henriques (2013), um elemento essencial na definição de comportamento é a propriedade de estimular os órgãos sensoriais (i.e., efeito da ocorrência).

Outro ponto em comum com o artigo de Todorov (2012), é o fato de considerar que o organismo é o meio pelo qual o comportamento ocorre. As covariações de interesse são sempre entre comportamento e ambiente. "Behavior analysts should not confuse their subjects, which are organisms, with their subject matter, which is not an organism (Tonneau, 2013, p. 69). Em todo o caso, a presença do organismo é um elemento imprescindível para a delimitação de comportamento e Tonneau (2013) utiliza a "pele" do organismo como o quadro de referência que permite observar o intercâmbio do organismo com o ambiente.

\section{ANÁLISE DOS ARGUMENTOS}

Os quatro artigos parecem possuir elementos em comum quando se propõem a definir comportamento, por exemplo, todos os artigos defendem em maior ou menor grau (de forma mais ou menos explícita) que comportamento é o objeto de estudos da Análise do Comportamento. Os dois primeiros artigos definem comportamento por meio do conceito de operante, o terceiro artigo apresenta comportamento, de forma mais ampla, com uma definição próxima à noção de contingência, e o último sugere um check list para se localizar comportamento como um evento.

\section{O COMPORTAMENTO DIANTE DO CONCEITO DE OPERANTE}

É importante destacar que Carrara e Zilio (2013) e Botomé (2013) focam sua análise, claramente, no conceito de operante (i.e., uma relação condicional de característica específica). A maior parte do texto de Carrara e Zilio (2013) dedica-se a um levantamento de definições de comportamento encontradas na literatura nos últimos 100 anos, todas criticadas. Quando Carrara e Zilio (2013) discorrem sobre o termo relações, eles estão ilustrando o conceito de contingência, ou seja, relações condicionais. Por condicionalidade, entenda-se correlação (Baum, 2012), ou o quanto as alterações sofridas por uma 
variável são acompanhadas por alterações na outra variável. Para que haja uma contingência, é preciso que a correlação entre a taxa de comportamento e a taxa de consequência (e.g., comida) mantenha-se em alta probabilidade, por exemplo. Entretanto, para se aferir a relação condicional entre os elementos, estes devem ser localizados, de forma que se possa, indubitavelmente, aferir a recorrência das ocorrências. Se a ciência em questão está interessada em explicitar as variações concomitantes entre variáveis independentes e variáveis dependentes, então cabe ao cientista denominar (i.e., operacionalizar) tais variáveis.

Carrara e Zilio (2013) utilizaram a análise do termo evento para argumentar que se comportamento for encarado como um evento, então suas ocorrências podem somente ser registradas, pois eventos não possuiriam uma res extensa, tanto quanto a noção de relação. Como pretexto, questionam se comportamento pode ter um significado próximo ao de resposta, ou seja, um evento que intermedeia as relações do organismo com o ambiente. Enquanto uma resposta é diretamente mensurada, o comportamento não pode ser, pois seria uma relação. As conclusões podem parecer sensatas, mas elas têm algumas implicações. Será que dizer que comportamento intermedeia é uma boa saída? A redação dos autores faz crer que comportamento é intercambiável com a expressão interação. Não interessa ao analista do comportamento observar um evento isolado, é claro, mas não se pode negar que um comportamento continua tendo propriedades físicas, queira o analista mensurá-la ou não. Se se quiser mensurá-lo, então irá atentar para a correlação entre suas propriedades e propriedades do ambiente. Neste momento, estará utilizando a noção de contingência e poderá conceituá-lo como operante ou respondente.

Botomé (2013), por exemplo, faz questão de utilizar a expressão atividade no lugar de resposta. $\mathrm{O}$ objetivo parece ser o mesmo, destacar que respostas ou classes de respostas não são a mesma coisa que comportamento. Enquanto as classes possuiriam propriedades espaço temporais, comportamento possuiria propriedades unicamente funcionais (para o autor, uma função especializada), ou seja, respostas e classes de respostas possuem propriedades físicas, ao passo que comportamento é relacional, portanto, operante. Todorov e Henriques (2013) destacam que...

"comportamento é classe, resposta é instância; respostas são definidas pela observação instantânea de um efeito, comportamento pela observação recorrente de efeito comum a todas as instâncias. Resposta é uma instância da classe comportamento" (p. 06).

Agora, se a classe será um operante ou não, dependerá das relações condicionais. A proposta de Todorov e Henriques (2013) é a de que comportamento não é nem o objeto do estudo, nem um evento discreto. Ele é parte do objeto de estudos, oferece propriedades dinâmicas passíveis de mensuração que, como tal, não acontece apenas uma vez no tempo e espaço, portanto uma classe. A unidade comportamento é aglutinada pela atividade constante ligada por um efeito comum. Quando esse comportamento for adjetivado por operante, poderse-á observar a covariação de suas características com outros eventos em curso e, neste momento, o pesquisador estará estudando interações, não comportamento em si. Seja como for, Todorov e Henriques (2013) continuam a defender a proposta de Todorov (2012) de que a definição de comportamento não pode ser a própria relação da qual ele participa. Questiona-se a definição de comportamento, acima de tudo, pelo uso do termo interação.

Todos os artigos citam a definição de 1938 de Skinner, em The Behavior of Organisms. Skinner faz do ambiente um referente para o comportamento. Mas o referente não é necessariamente um referente funcional, pois, naquele momento, Skinner estava operacionalizando o termo. Skinner destaca a participação ambiental na identificação da parte do funcionamento de interesse, mas o que ele está destacando é que o ambiente oferece o quadro relacional para a identificação das características espaço-temporais do comportamento (i.e., deve gerar efeitos ambientais que serão, prontamente, identificáveis). Os autores atuais quando se referem ao comportamento como interação, e para isso recorrem à necessidade de se apontar o vínculo ambiental para defini-lo, se referem à contingência operante.

Todorov (2012) e Todorov e Henriques (2013) não questionam que o operante seja um dos objetos, mas questionam que nem de longe se pode emparelhar o conceito ao termo comportamento (um dos eventos que faz parte do objeto de estudo). Tanto Botomé (2013) quanto Carrara e Zilio (2013) transparecem que uma perspectiva semelhante à proposta por Todorov (2012) pode ser "interpretado como uma forma reducionista de descrever o comportamento no sentido de 'o que o organismo faz' " (Carrara \& Zilio, 2013, p. 13). Discordamos desta perspectiva. Se o objetivo do pesquisador é estabelecer um vínculo relacional (relação condicional), então ele precisa especificar qual efeito (manifestação) uma atividade deve ter para que seja selecionada. Quando o pesquisador procede assim, ele está simplesmente "localizando" comportamento (em um sentido próximo ao de Todorov [2012] e Todorov \& Henriques [2013]), mas se o objetivo for analisar o processo obtido, então o comportamento deverá ser observado ao longo das interações. Semelhante ao artigo de Todorov que deu partida a este volume especial, autores como Rein e Svartdal (1979) já questionavam o uso do operante como análogo ao uso ordinário de comportamento. A distinção entre "atividade" e "comportamento" parece repousar no pressuposto de que o comportamento não pode ser identificado independentemente, uma vez que o termo não poderá ser aplicado a menos que o vocabulário técnico comportamental seja utilizado. A atividade linguística proposta por Botomé (2013) seria enfadonha. Na definição de comportamento de Botomé (2013), por exemplo, comportamento seria definido pelo resultado histórico de relações específicas e especializadas (operantes). Os analistas estariam sempre diante do problema de saber que tipo de comportamento se está 
estudando até que as contingências para o comportamento sejam esclarecidas.

How is it possible to specify contingent control conditions for a certain behaviour (and explain the behaviour as a function of the control conditions) if the behaviour is defined by these control conditions?" (Rein \& Svartdal, 1979, p. 68-69).

\section{O OPERANTE COMO UMA CONTINGÊNCIA ESPECÍFICA: INTERAÇÕES COMO OBJETO DE ESTUDO}

Todorov (2012) e Todorov e Henriques (2013) concordam com a apreciação de Botomé (2013), segundo a qual estudar somente uma parte da interação é uma abordagem parcial. Todorov e Henriques (2013) procuraram demonstrar este fato considerando que definir o objeto de estudos da Análise do Comportamento como "o" comportamento e defini-lo como interação organismo e ambiente é abordar o fenômeno somente do ponto de vista operante, portanto, parcialmente. Este hábito desconsidera outras contingências, algo que foi comum a Watson (por falta de desenvolvimento científico) e que mereceu as críticas de Russell. Skinner não se posicionou de maneira muito diferente. Sua definição de comportamento e sua obra em geral se vinculam, muito estreitamente, com a definição de operante. A quantidade massiva de artigos empíricos e teóricos em torno do operante destaca que outras contingências são negligenciadas pelos analistas. É importante fazer a ressalva de que Skinner tinha um posicionamento epistemológico muito mais amplo do que Watson. A despeito disto, suas análises sempre se concentraram no comportamento operante.

Em uma interpretação livre e despretensiosa, acredita-se que o termo comportamento foi cunhado como um evento verbal de contra controle. Ainda nos dias de hoje, a expressão causa alarde aos adeptos da psicologia mentalista. Considerar o comportamento como objeto de estudos em si é uma maneira de se posicionar em clara divergência com a prática tradicional de conceber o comportamento como evidência de algo subjacente. Analistas descrevem somente relações ordenadas e sistemáticas entre comportamento e ambiente, sem inferências causais. Por isso o destaque para o termo comportamento, mas ao fim e ao cabo, são relações o que se estuda. Não faz sentido estudar comportamento isolando-o do ambiente. Todorov (2012) apenas discorda que não seja possível apontar para um comportamento sem menção às relações funcionais.

O termo operante designa um tipo de relação funcional específica, tanto quanto o termo respondente. Relação funcional é contingência, não comportamento. Quando Botomé (2013) insistentemente utiliza a expressão "comportamento reflexo", por exemplo, faz parecer que contingência e comportamento são um só conceito. Se considerarmos que respondentes e operantes são categorias amplas de contingências e que contingências são descrições de relações condicionais (interações), então o autor está parcialmente correto, operante é um dos objetos. Os desdobramentos da pesquisa operante são de grande valor para a compreensão de processos psicológicos, apenas há desacordo que este seja um objeto análogo a comportamento. Neste ponto, as definições levantadas por Lazzeri (2013) apresentam uma grande vantagem em relação ao posicionamento de Carrara e Zilio (2013) e Botomé (2013), elas permitem observar outras contingências. Quando Todorov (2012) e Todorov e Henriques (2013) apresentam que um comportamento pode ser designado apontando-se especificamente para seu efeito, eles também abrem as portas para as contingências respondentes. A diferença entre Todorov e Lazzeri é que o segundo alinha comportamento a contingências.

Quando Botomé (2013) caracteriza comportamento como uma categoria ampla de fenômenos, ele o está partindo do pressuposto de que comportamento se equivalha ao processo, em estado estável, produzido por um procedimento específico. Uma relação condicional em estado estável pode facilmente receber um rótulo, mas isso não quer dizer que o termo descreva o processo (e.g., o caso do autocontrole anteriormente citado). Todorov (1983) e Galbicka (1992), por exemplo, chamam atenção para a negligência na área por estudos de estados de transição. Argumentam que os estudos de transição preocupam-se em desvelar os processos que modificam a estrutura do comportamento, no tempo e no espaço, em algo inteiramente novo. $\mathrm{O}$ "comportamento", neste caso, não é um termo molar, mas um elemento da interação. $\mathrm{O}$ aprimoramento da contingência operante...

for the first time provided a mechanism by which behavior could freely change from one spatiotemporal set of characteristics to any other, through a seemingly endless number of pathways. Behavior change was the operant" (Galbicka, 1992, p.243).

A única categoria ampla de fenômenos é o operante. Um segundo ponto é que Botomé (2013) considera que comportamento pode ser examinado em tipos, extensão e profundidade. A análise experimental utiliza o comportamento somente como o catalizador das interações operantes. Quando se diz estar estudando momentum comportamental (rasamente definido aqui como resistência à mudança), não se pode afirmar que resistência é um tipo de comportamento, um "fazer" do organismo. O momentum é uma característica comportamental, um processo obtido dado o arranjo condicional entre as variáveis envolvidas no estudo. $\mathrm{O}$ estudo do momentum não objetiva se aprofundar em um tipo de comportamento, objetiva aprofundar-se na covariação entre parâmetros das variáveis independentes e das dependentes para explicar um processo que se manifesta em qualquer que seja a unidade (comportamento). O comportamento pode ser bicar ou pressionar, não importa, é a interação que se pretende estudar. O comportamento não é o fenômeno estudado, é um evento (elemento) utilizado para se falar sobre interações. Quando caracterizo o bicar como resistente à 
mudança, eu o faço utilizando a expressão momentum como um termo disposicional; ele ajuda a descrever as características que o bicar terá ou tem, se dadas condições estiverem presentes. Interessa ao analista do comportamento estudar questões humanas como as neuroses, mas neurose não é comportamento; aquilo que alguém faz e que ganha o nome de neurose é que é o comportamento. É possível apontar para aquilo que alguém faz e que ganha tal rótulo, mas o evento apontado só poderá ser explicado (em suas características) observando-se as interações mantidas, é claro.

O mesmo equívoco acontece ao discutir as diferenças conceituais entre classe de respostas e operante. Todorov e Henriques (2013) destacam que...

comportamento é classe, resposta é instância; respostas são definidas pela observação instantânea de um efeito, comportamento pela observação recorrente de efeito comum a todas as instâncias. Resposta é uma instância da classe comportamento" (p. 76).

Agora, se a classe será um operante ou não, dependerá das relações condicionais.

Dizer que "operante" é uma forma de comportamento (Todorov, 2012) e dizer que "sua definição como a interação da qual faz parte parece vir de uma confusão entre efeito e consequência", e completar com um exemplo que "um mero aceno de mão tem como efeito o deslocamento do ar, alguém acenando de volta é a consequência" parece ser insuficiente em relação ao que se evidencia a respeito da diferença entre atividade do organismo e suas interações com os aspectos do meio com o qual, de alguma forma, essa atividade configura uma interação específica (Botomé, 2013, p. 34).

Botomé (2013) parece não ter compreendido a proposta. O efeito para Todorov (2012) é uma manifestação, uma decorrência (ou resultado) da atividade do organismo, como o deslocamento do ar no abanar de mão ou ondas sonoras na vocalização. Consequência é um evento subsequente ao efeito da atividade e que mantém relação condicional com ambos. No texto de Botomé, o leitor é desafiado a denominar um comportamento pela expressão "limpar uma mesa". Percebam o equívoco do autor. "Limpar" é uma categoria ampla (i.e., um operante), não é uma ocorrência. Instiga, também, os leitores a avaliarem se é suficiente observar o "esfregar a mesa" para denominar o "limpar". Esfregar a mesa é sem dúvida um comportamento (o efeito neste caso pode ser inferido), mas até então não se pode especificar de qual tipo de contingência operante ele participa. Todorov (2012) e Todorov e Henriques (2013) distinguem comportamento de operante quando propõe a diferenciação entre efeito e consequência. Operante e respondente são descrições funcionais, que podem ser caracterizadas em função das possibilidades de análises. Definir uma interação apontando para as consequências é definir a contingência operante. Definir comportamento como uma classe de respostas que produz um efeito distinguível no ambiente é diferente. As atividades organísmicas eliciadas durante um período de abstinência são comportamento, não necessariamente operante. Elas têm um efeito discernível, mas a relação que esse efeito mantém é com os eventos antecedentes eliciadores. É possível distinguir um comportamento observando o esfregar (seus efeitos); é possível explicar porque esse esfregar recorre observando sua relação condicional com outros eventos; isso é operante.

Uma contingência estabelecida, seja com selecionadores atrasados ou não, é o que define o uso de termos psicológicos. Neurose não é comportamento. Comportamentos ditos molares são descrições dos resultados das contingências; eles não apontam para o comportamento no sentido de apontar para ocorrências, mas para a tendência a (...). Os comportamentos, as atividades que são incluídas no termo, podem sim ser localizados e agrupados em classes com referência aos seus efeitos. O posicionamento de Todorov e Henriques (2013) é muito próximo ao de Shirck (1971) para o qual "effects of responses must be effects upon which reinforcement can be made contingent" (p.422).

\section{COMPORTAMENTO-AMBIENTE OU ORGANISMO- AMBIENTE?}

A maior parte dos autores afirmaram que a relação estudada pela Análise do Comportamento é organismoambiente. Todorov (2012) e Todorov e Henriques (2013) preferem coadunar, em partes, com autores como Lee (1992) e Palmer (2003). Ao analisarem o objeto de estudos e sua unidade de análise, discordam que esta seja relações entre organismo e ambiente. Um quesito básico para fortalecer a argumentação é o fato de a unidade de medida não aferir mudanças organísmicas (não que não possam ser medidas quando em relação condicional arbitrariamente estabelecida [Sassmor, 1966]). Na medida em que não se exige um olhar exclusivo para o organismo, é possível dizer que analistas do comportamento estudam mudanças em propriedades dinâmicas de comportamento, estudam interações comportamento-ambiente, atentam para as propriedades das mudanças comportamentais.

Afirmar que o comportamento é uma parte do funcionamento do organismo não significa localizar o comportamento no organismo. Significa dizer que organismos vivos funcionam de diferentes maneiras sendo uma delas o objeto da Psicologia. Já foi argumentado anteriormente que não interessam as mudanças organísmicas. O comportamento não ocorre "no" organismo, ele ocorre "por meio" do organismo; é executado "pelo" organismo e não "localizado" no organismo. Não se pode abrir o organismo e localizar o comportamento, como quem abre uma caixa e encontra coisa dentro.

Tonneau (2013) emparelha comportamento a mudanças em estruturas organísmicas ao apontar para a "pele" como um delimitador. Talvez o único problema em sua definição seja considerar que o efeito deva se dar na barreira biológica entre o interior do organismo e o seu exterior (apesar de ponderar que a barreira pode estar 
dentro do organismo). Os demais itens de seu check list se referem ao caráter biológico do sistema (o que eliminaria comportamento de robôs, da definição). Contudo, o fechamento do circuito eletrônico durante a pressão à barra é um efeito da atividade que não se limita a uma alteração na forma da superfície do corpo, e é a condição necessária e suficiente para que uma relação condicional se estabeleça no laboratório. Ademais, posta o problema de como reunir instâncias em uma classe, desde que o "efeito na pele" pode ser diverso (e.g., pressionar a barra de diferentes maneiras) enquanto o efeito ambiental permanece o mesmo (i.e., fechamento do circuito). Qual dos efeitos melhor caracterizaria comportamento? Ao adotar e tentar melhorar a definição de Skinner (1938), Tonneau (2013) implicitamente concorda com Todorov (2012), comportamento não é a interação organismo-ambiente.

\section{CONCLUSÃO}

Argumenta-se que o comportamento, propriamente dito, não é o objeto de estudos da Análise do Comportamento (Todorov, 2012, Todorov \& Henriques, 2013). Definindo uma instância de comportamento (resposta) com base no seu efeito, Todorov (2012) e Todorov e Henriques (2013) estão implicitamente propondo que há dois tipos de perguntas que podem ser feitas diante do evento: a primeira se refere à localização (i.e., à observação, ao apontamento) do comportamento; outra pergunta diz respeito à "causa" do comportamento. Para responder a primeira, é preciso critérios claros e objetivos; elencamos as propriedades dinâmicas do comportamento, fornecidas por um quadro de referência estabelecido pelo próprio organismo (Tonneau, 2013) ou pelo ambiente (i.e., o efeito e sua propriedade espaço-temporal) (Todorov, 2012, Todorov \& Henriques, 2013). Para responder à segunda, é preciso verificar se este é, em primeiro lugar, meu objeto de estudos (para isso, pode-se dispor das definições de Tonneau [2013] e Lazzeri [2013]). Respostas à primeira versam sobre eventos; respostas à segunda consideram contingências, ou o valor de existência do evento ou, ainda, como o evento adquiriu a característica que se apresenta. Se e uma pessoa erguer a mão e como efeito projetar uma sombra, isso será uma ocorrência. Saber se essa ocorrência mantém relação condicional com o ambiente é que vai delimitar a ocorrência como objeto de estudos.

Analistas do comportamento estudam interações comportamento-ambiente, não organismo-ambiente (Todorov, 2012). Se aceitarmos as ponderações de alguns dos autores, "Análise do Comportamento" acaba ficando como nome de fantasia, marca comercial, daqueles que estudam interações. Nós defendemos "Análise do Comportamento" como nome da abordagem porque a Psicologia não estuda qualquer interação organismoambiente; seu objeto de estudo são interações comportamento, ou de produtos de comportamentos entrelaçados, e ambiente (Todorov, 1983, 1989/2007, 2012).
Se a definição modernizada será útil ou não vai, depender da comunidade verbal selecionadora composta pelos milhares de analistas do comportamento que publicam e ensinam hoje. Nesse sentido, comportamento não é, mas poderá vir a ser, definido segundo umas dessas propostas publicadas neste número da Revista Brasileira de Análise do Comportamento.

\section{REFERÊNCIAS}

Baum, W. M. (2012). Rethinking reinforcement: allocation, induction and contingency. Journal of the Experimental Analysis of Behavior, 97, 101-124.

Botomé, S. P. (2013). O conceito de comportamento operante como problema. Revista Brasileira de Análise do Comportamento, 9(1), 19-46.

Carrara, K., \& Zilio, D. (2013). O comportamento diante do paradigma behaviorista radical. Revista Brasileira de Análise do Comportamento, 9(1), 1-18.

Catania, A. C. (1973). The concept of the operant in the analysis of behavior. Behaviorism, 1, 103-116.

Galbicka, G. (1992). The dynamics of behavior (Editorial). Journal of the Experimental Analysis of Behavior, 57, 243-248.

Lazzeri, F. (2013). Um estudo sobre definições de comportamento. Revista Brasileira de Análise do Comportamento, 9(1), 47-65.

Lee, V. L. (1992). Transdermal interpretation of the subject matter of behavior analysis. American Psychologist, 47, 1337-1343.

Palmer, D. K. (2003). Specifying psychology's observable units: Toward an integration of Kantor's behavior segment, Skinner's operant, and Lee's deed. Behavior and Philosophy, 31, 81-110.

Rein, J. G., \& Svartdal, F. (1979). Limitations of Skinner's concept of an operant: A theoretical note. Scandinavian Journal of Psychology, 20, 65-70.

Sassmor, R. M. (1966). Operant conditioning of a smallscale muscle response. Journal of the Experimental Analysis of Behavior, 9, 69-85.

Todorov, J. C. (1983). Estados de transição e estados transitórios. Anais da XIII Reunião Anual de Psicologia, 13, 327-342.

Todorov, J. C. (1989). A Psicologia como estudo das interações. Psicologia: Teoria e Pesquisa, 5(3), 347356. Reimpresso em Psicologia: Teoria e Pesquisa (2007), 23, 57-61.

Todorov, J. C. (2012). Sobre uma definição de comportamento. Perspectivas em Análise do Comportamento, 3, 32-37.

Todorov, J. C., \& Henriques, M. B. (2013). O que não é e o que poderia vir a ser comportamento". Revista Brasileira de Análise do Comportamento, 9(1), 74-78.

Tonneau, F. (2013). Behavior and the skin. Revista Brasileira de Análise do Comportamento, 9(1), 66-73. 